\title{
Impact of land use on urban mobility patterns, emissions and air quality in a Portuguese medium-sized city
}

\author{
Jorge M. Bandeira ${ }^{\mathrm{a}, *}$, Margarida C. Coelho ${ }^{\mathrm{a}}$, Maria Elisa Sá ${ }^{\mathrm{b}}$, Richard Tavares ${ }^{\mathrm{b}}$, Carlos Borrego ${ }^{\mathrm{b}}$ \\ ${ }^{a}$ University of Aveiro, Department of Mechanical Engineering, Centre for Mechanical Technology and Automation, Campus Universitário de Santiago, $3810-193$ Aveiro, Portugal \\ b University of Aveiro, Department of Environment, Centre for Environmental and Marine Studies, University of Aveiro, Campus Universitário de Santiago, 3810-193 Aveiro, Portugal
}

\section{A R T I C L E I N F O}

Article history:

Received 27 April 2010

Received in revised form 10 November 2010

Accepted 3 December 2010

Available online 8 January 2011

\section{Keywords:}

Land use

Mobility

Emissions

Air quality

Integrated modeling

\begin{abstract}
A B S T R A C T
The main objective of this work was to evaluate the impact of urban development trends in mobility patterns of a medium sized Portuguese city and air quality consequences, using a sequential modeling process, comprising i) land use and transportation, TRANUS model; ii) road traffic air pollutants emissions, TREM model and; iii) air quality, TAPM model. This integrated methodology was applied to a medium sized Portuguese city. In order to evaluate the implementation of the methodology, a preliminary study was performed, which consisted on the comparison of modeled mobility patterns and $\mathrm{CO}$ and $\mathrm{PM}_{10}$ concentrations with measured data used in the definition of the current scenario. The comparison between modeled and monitored mobility patterns at the morning peak hour for a weekday showed an RMSE of $31 \%$. Regarding CO concentrations, an underestimation of the modeled results was observed. Nevertheless, the modeled $\mathrm{PM}_{10}$ concentrations were consistent with the monitored data. Overall, the results showed a reasonable consistency of the modeled data, which allowed the use of the integrated modeling system for the study scenarios.

The future scenarios consisted on the definition of different mobility patterns and vehicle technology characteristics, according to two main developing trends: (1) "car pooling" scenario, which imposes a mean occupancy rate of 3 passengers by vehicle and (2) the "Euro 6" scenario, which establishes that all vehicles accomplish at least the Euro 6 standard technology. Reductions of $54 \%$ and $83 \%$ for $\mathrm{CO}, 44 \%$ and $95 \%$ for $\mathrm{PM}_{10}$, $44 \%$ and $87 \%$ for $\mathrm{VOC}$ and $44 \%$ and $79 \%$ for $\mathrm{NO}_{\mathrm{x}}$ emissions were observed in scenarios 1 and 2, respectively. Concerning air quality, a reduction of about $100 \mu \mathrm{g} \mathrm{m} \mathrm{m}^{-3}$ of $\mathrm{CO}$ annual average concentration was observed in both scenarios. The results of $\mathrm{PM}_{10}$ annual concentrations showed a reduction of $1.35 \mu \mathrm{g} \mathrm{m}^{-3}$ and $2.7 \mu \mathrm{g} \mathrm{m}^{-3}$ for scenarios 1 and 2 respectively.
\end{abstract}

(C) 2010 Elsevier B.V. All rights reserved.

\section{Introduction}

In Europe, emissions of greenhouse gases (GHGs) from transport (excluding international aviation and maritime transport) increased by $28 \%$ between 1990 and 2007 and now account about 20\% of total emissions. Regarding local pollutants, despite significant past emission reductions the contribution of the road transport sector to total European emissions remains considerable (EEA, 2010). Apart from significant reductions that can be achieved through the penetration of new technologies in the automobile industry (Kousoulidou et al. 2008), local authorities have a range of tools they can use to improve air quality. Low emission zones (in combination with retrofit initiatives), traffic planning, and measures aiming at a shift of motor

\footnotetext{
* Corresponding author. Tel.: +351 964102982; fax: +351234370309. E-mail addresses: jorgebandeira@ua.pt (J.M. Bandeira), margarida.coelho@ua.pt (M.C. Coelho), mariaelisasa@ua.pt (M.E. Sá), richard.tavares@ua.pt (R. Tavares), cborrego@ua.pt (C. Borrego).
}

vehicle mileage, are all examples of important management elements to reduce air pollutant concentrations. The response to date in many European cities has been to rely on the development of integrated transport systems, the introduction of road pricing and workplace parking charges, or the revitalization of bus services (Pooley and Turnbull, 2005). However, nowadays there is recognition that other measures to restraint traffic levels are necessary.

Not much research was found analyzing the issue of policy integration, particularly in relation to transport, land use planning and environment policies. However, today it is widely accepted by the scientific community, that there is a relationship between the urban planning (city form, size, density and land use), and its sustainability. However, the consensus about the exact nature of this relation has not yet been reached (Williams et al., 2000; PLUME, 2003; De Ridder et al., 2008a, b; Borrego et al., 2006). Debates on the urban structure have become strongly polarized between the advocates and opponents of the traditional compact and the sprawled city (De la Barra et al., 1998; Williams et al., 2000). According to Reid et al. (2008) a reduction of greenhouse gases up to $10 \%$ in 2050 , may result only from changes in 
land use through compact development. Moreover, additional reductions may result from employing other strategies such as transit investment, fuel pricing, and parking.

Over the last decades several empirical and modeling studies have been performed, integrating land use, mobility, emissions and its relationship with urban structures. One of the first attempts to link two types of models for regional policy assessments was made by Johnston and de la Barra (2000) through the representation of both land and travel markets with zones and networks. More recently, Lam and Niemeier (2005) have developed an exploratory simulation model to study the effects of land-use policies on transportation activities and vehicle emissions. Morton et al. (2007) have also developed a land use-transportation-emissions model for Charlotte, North Carolina. What has arisen from the existing literature review is that relatively few studies have explored the connection to air quality (Marquez and Smith, 1999; Marshall et al., 2005; Lam and Niemeier, 2005; Borrego et al., 2006; EC, 2007; De Ridder et al., 2008a). Most of the work was performed for imaginary cities (Borrego et al., 2006), existing highly urbanized metropolitan regions (Civerolo et al., 2007; De Ridder et al., 2008a, b) or at a local scale (Borrego et al., 2003), but none for medium sized cities. Moreover, the authors did not find any studies concerning the analyses of land use and mobility integrated with emissions and pollutants dispersion modeling in a medium-sized city.

The main objective of this work is to evaluate the consequences of current patterns of land use and transportation in terms of energy and emissions impacts in a medium-sized city. Secondly, it is intended to study the potential effects of policy changes in the field of mobility or technological advances in automotive industry. A methodology based on successive modeling of transport and land use, emissions/fuel consumption and air quality has been developed and applied to a case study.

\section{Methodology}

A sequential modeling process comprising: the land use and transportation - TRANUS (Transpuertes y Uso del Suelo) (Modelistica, 2007), the road traffic air pollutants emissions - TREM (Transport Emission Model for line sources) (Borrego et al, 2003) and the air quality -TAPM (The Air Pollution Model) (Hurley et al, 2005) (as shown in Fig. 1) was applied to a baseline scenario (current situation) and two future scenarios to evaluate the potential impacts of land use on urban mobility and air quality in a selected mediumsized city. The main elements analyzed were: 1) the traffic flows on the main network of Aveiro; 2) the urban traffic related to fuel consumption and atmospheric pollutants emissions, namely, $\mathrm{CO}_{2}, \mathrm{CO}$, VOC, $\mathrm{NO}_{\mathrm{x}}$ and $\mathrm{PM}_{10}$ and 3 ) the assessment of air quality with observed values, specifically $\mathrm{CO}$ and $\mathrm{PM}_{10}$ concentrations.

The selection of the study area, scenarios and the components of the sequential modeling process are described below.

\subsection{Case study}

The city of Aveiro consists of a medium sized urban area, located in the north-center region, near the western coast of Portugal, at $60 \mathrm{~km}$ south from Oporto. According to the 2001 national census (INE, 2001) Aveiro has a population of about 55,000 inhabitants. Currently, the city faces some problems related to mobility, in particular, the high use of private vehicles in contrast with the poor use of public transportation. The outskirts of Aveiro are built primarily in semirural areas with low population density, hindering the public transportation efficiency and encouraging the use of private vehicles. Concerning local/regional air quality there is an Air Quality Monitoring Station (AQMS) in Aveiro, in which several air pollutants are monitored, including particulate matter $\left(\mathrm{PM}_{10}\right)$ and ozone $\left(\mathrm{O}_{3}\right)$. The mentioned pollutants are of special concern because exceedences to the correspondent legislated limit values have been registered over the last years.

The analysis of the city development patterns in recent years showed that Aveiro city growth has occurred mainly within the A25 motorway and the EN109 roadway, covering an area of $6.5 \mathrm{~km}^{2}$. To characterize the traffic fluxes in the main road segments, two data sets gathered between October and November 2008 have been used. The first monitoring campaign was performed by the Municipality of Aveiro in six main intersections using traffic counting equipment through Doppler Effect (DE counts). In order to fulfill required information for the transport model (TRANUS) calibration and to complement DE counts, a second traffic monitoring campaign was performed at the same time, through traffic video recordings (VR counts).These counts were done on the 6 main arterials that converge into the city center. The monitoring points used in both campaigns and the study area are identified in Fig. 2.
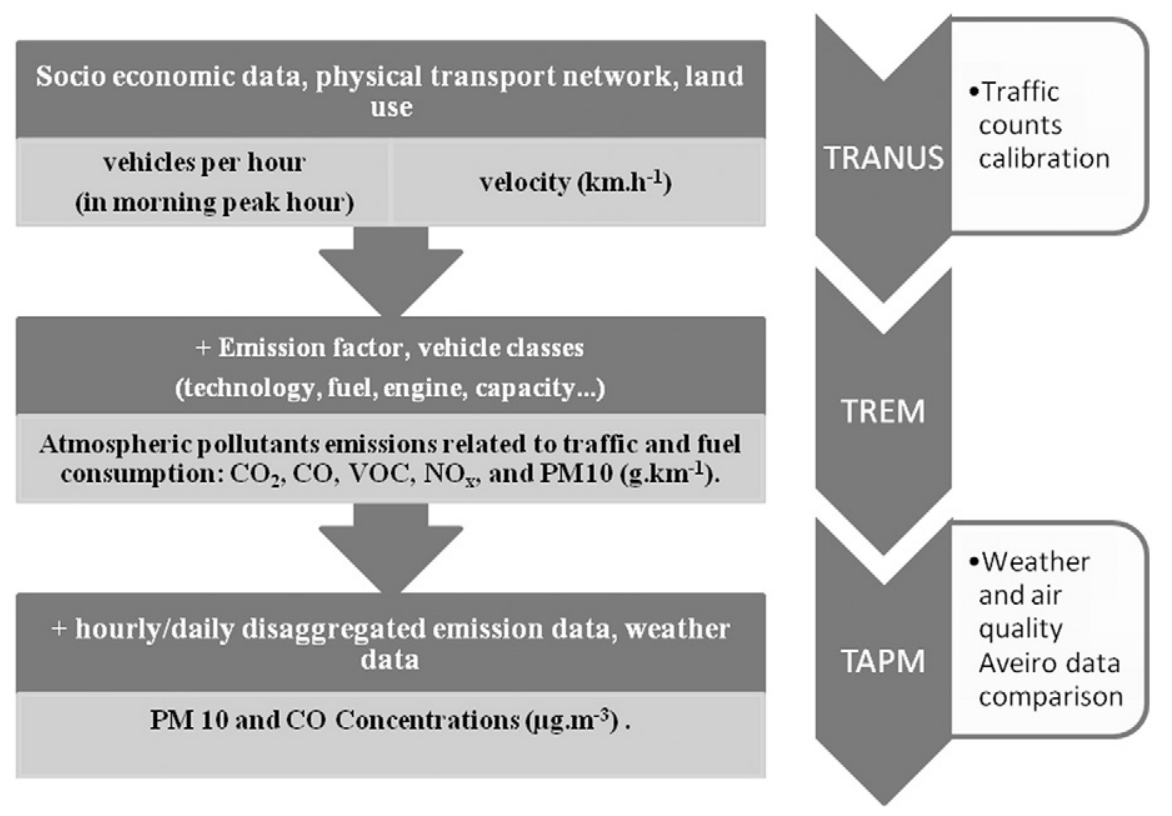

Fig. 1. Structure of the research. 

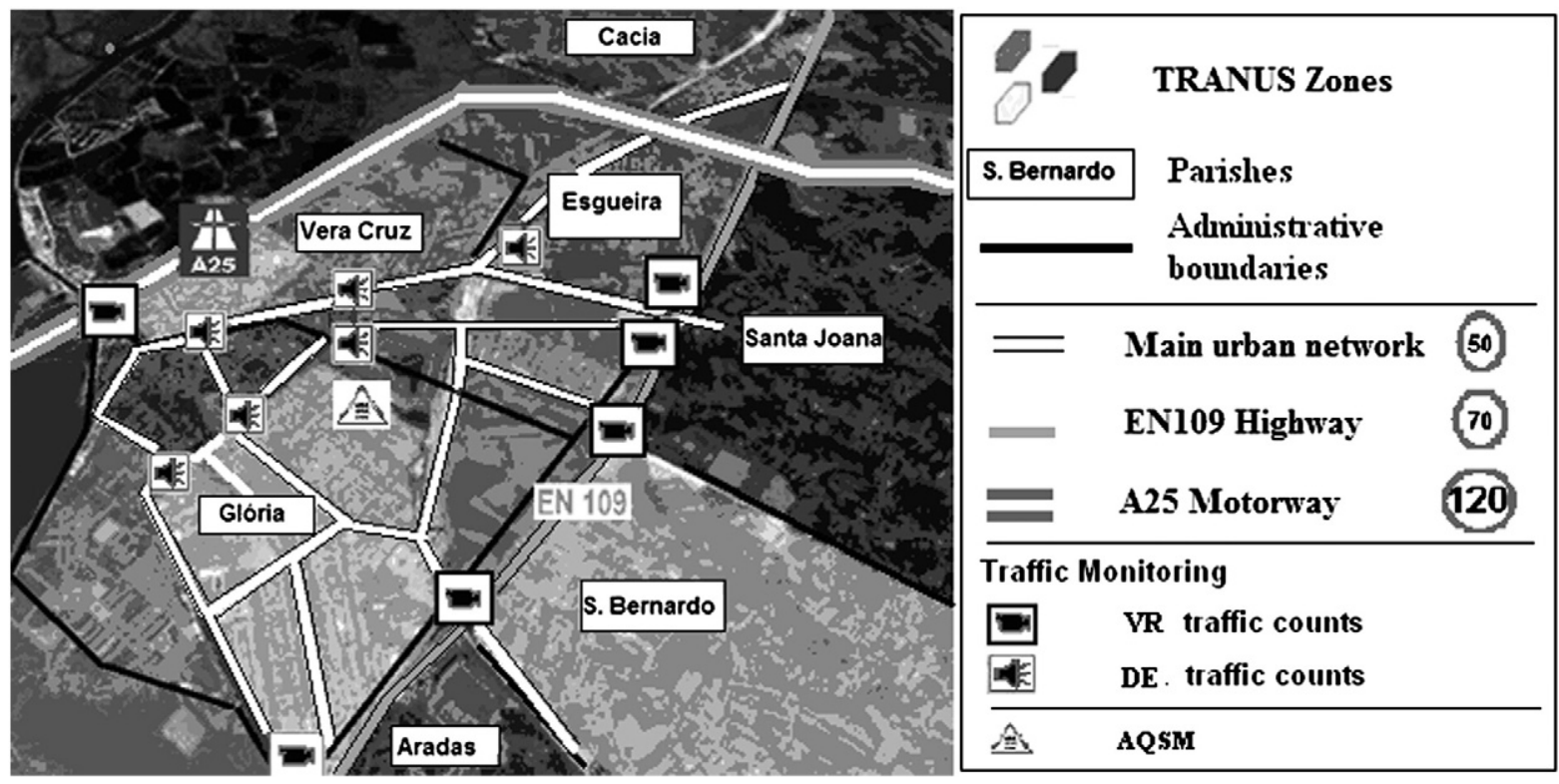

Fig. 2. Map of the study area.

\subsection{Study scenarios}

To assess the implementation of the methodology three study scenarios were defined: a baseline scenario and two future scenarios. The baseline scenario intended to characterize the present situation. The future scenarios were defined considering distinct mobility patterns (scenario 1) and vehicle technology characteristics, according to the developing trends (scenario 2). Scenario 1 aims to evaluate the effects due to the increase of vehicle occupancy rate, by means of sustainable mobility measures such as car pooling. A sensitivity analysis was carried out, increasing the occupancy rate of the vehicles from the current value of 1.5 to 3 . It must be emphasized that the main focus was to evaluate the impacts on air quality from the mobility pattern trends based on occupancy rate increase, and not how it can be achieved. Through scenario 2 the evaluation of pollutant emissions and effects on air quality was performed considering that all vehicles met the currently available most recent European standards of emissions (Euro 6). "Euro" refers to the European Union (EU) Emission Standards (DieselNet, 2007) for exhaust emission limits of new vehicles sold in EU member states. Compliance is determined by running the vehicle on a chassis dynamometer for a standardized test cycle. The Euro 1 to Euro 6 emission standards are progressively more stringent and apply to all passenger vehicles that were built from July 1992 (Euro 1) and those that will be built after September 2014 (Euro 6) (Coelho et al., 2009a). Therefore, this scenario considers that all passenger cars belong to the class Euro 6 and vehicles would meet the most stringent criteria.

An additional scenario considering a new connection from the motorway A25 towards the city center was also defined. However, this scenario showed no relevant differences in the urban traffic patterns. Since the emission impact of this change would be negligible, the results are not presented in this paper.

\subsection{Integral modeling platform}

\subsubsection{Land use and transport modeling}

The TRANUS model was developed by Modelistica. This tool is an integrated land use and transport modeling system that reproduces the location of activities in space, land use, the real estate market and the transportation system. One of the most worthy features of this system is the technique in which all components of the urban system are integrated, such as the location of activities, land use and the transport system (Modelistica, 2007). Trips are explained as the result of the economic and spatial interactions between activities and the transportation system.

For the modeling process it is implicit that the basic employment (Agriculture and Industry Sectors) is a completely exogenous factor, i.e., it is considered that the production of this sector is not a demand of other sectors, being equivalent to the final demand in insumeproduct models. Its allocation just depends on policy resolutions or external factors not modeled by TRANUS. However, this production depends on other inputs like population and land. Population and service employment sectors are considered induced, since they represent the production sector generated within the study area to guarantee the demand of other sector (Modelistica, 2007). To be able to fulfill its function, service employment consumes units of land (space) and population. On the other hand, population needs to consume units of service employment to meet their needs and land (place to build their houses).

In TRANUS the movements of people or goods are assigned between zones defined by the user. In the study case, zone limits were defined via the administrative boundaries (for suburban areas), and the homogeneity of territories, existing physical features, and analysis of the current development trends (for city center - Gloria and Vera Cruz parishes) totaling 20 zones. Given the dimension of the city, several zones within the same administrative structure had to be considered. Since there is no statistical data available for smaller scales than the administrative boundaries (see Fig. 2), some assumptions are needed in order to characterize the socio-economic composition of the internal zones. Taking into account these difficulties, a four-sector structure was defined:

- Population (inhabitants);

- Basic employment (jobs in the primary and secondary sectors);

- Service employment; and

- Land (available construction area).

It is assumed, therefore, that the socio-economic structure is simplified in a single social stratum and all economic activities are grouped into two distinct sectors (Basic and Services).

Table 1 indicates the required data for each category and the original source.

The VR counts (comprising a sample of 3500 vehicles) analysis showed that light duty vehicles represent more than $97 \%$ of the city fleet. Additionally, given the limited demand and supply of public 
Table 1

Structure of input data used in TRANUS: economical sectors, physical and operative supply for transportation.

\begin{tabular}{|c|c|c|c|}
\hline $\begin{array}{l}\text { Sector and other } \\
\text { parameters }\end{array}$ & Category & Data & Sources of data \\
\hline $\begin{array}{l}\text { Basic } \\
\text { employment } \\
\text { Service } \\
\text { employment }\end{array}$ & $\begin{array}{l}\text { Agriculture, } \\
\text { industry } \\
\text { Retail, } \\
\text { education } \\
\text { health, etc. } \\
\text {... }\end{array}$ & $\begin{array}{l}\text { Number of jobs, minimum and } \\
\text { maximum input demand by } \\
\text { output unit }\end{array}$ & $\mathrm{PSO}^{\mathrm{a}}$ \\
\hline Land & $\begin{array}{l}\text { Available } \\
\text { construction } \\
\text { area }\end{array}$ & $\begin{array}{l}\text { Area (ha) and rent in } € \text { per } \\
\text { hectare per month }\end{array}$ & $\begin{array}{l}\text { Reports from } \\
\text { the local and } \\
\mathrm{AM}^{\mathrm{b}}\end{array}$ \\
\hline Population & Inhabitants & $\begin{array}{l}\text { Average income, value of travel } \\
\text { time, value of waiting time }\end{array}$ & PSO, SP \\
\hline $\begin{array}{l}\text { Transportation } \\
\text { modes }\end{array}$ & $\begin{array}{l}\text { Car } \\
\text { Non- } \\
\text { motorized }\end{array}$ & $\begin{array}{l}\text { Average occupancy, operations } \\
\text { costs, free flow speed, flow at } \\
\text { peak hours for major roads }\end{array}$ & $\begin{array}{l}\text { GEPD }^{\mathrm{d}} \text {, } \\
\text { Modelistica, SP }\end{array}$ \\
\hline Road network & $\begin{array}{l}\text { Motorway } \\
\text { Main Road } \\
\text { Arterial } \\
\text { Sub-arterial } \\
\text { Connection } \\
\text { road }\end{array}$ & $\begin{array}{l}\text { Name, length, authorized } \\
\text { modes, carrying capacity, free- } \\
\text { flow, speed, \% speed reduction } \\
\text { at volume capacity }<1, \mathrm{~V} / \mathrm{C} \text { at } \\
\text { Max speed reduction, etc.... }\end{array}$ & $\begin{array}{l}\text { Reports from } \\
\text { the study area, } \\
\text { Modelistica... }\end{array}$ \\
\hline
\end{tabular}

a Planning Studies Office - Ministry of Labor and Social Solidarity.

b Aveiro Municipality.

c Statistics Portugal.

d Geology and Energy Portuguese Directorate.

transportation and the main goal of this work, only private vehicles were considered as operative supply. According to the Census 2001 (INE, 2001), less than $8 \%$ of trips are via public transportation and the last 30 years demonstrated a significant decreasing trend. Home based Work and Home based services trips (whose destinations are: Education, Health, and Administrative Services or Shopping) were simulated at the morning peak hour. From monitored traffic data a peak is observed between 8:15 AM and 9:15 AM, approximately equivalent to $10 \%$ of the daily traffic. To achieve a more realistic simulation, trips to and from adjacent municipalities were exogenously introduced from available information at 2001 census Portugal Statistics (INE, 2001).

TRANUS uses a probabilistic logit model for assignment. Convergence is checked for all links as the variation between the current iteration and the previous, considering two variables: operating speeds and traffic volume.

\subsubsection{Emission modeling}

The Transport Emission Model for Line Sources (TREM) was developed at the University of Aveiro, to support the quantification of emissions induced by road traffic with high temporal and spatial resolution to be used in air quality modeling. The model is based on the emission functions derived from the MEET/COST methodology (Borrego et al., 2003). The emission rates for several atmospheric pollutants and fuel consumption are estimated as a function of average speed. Different technologies (engine type, model year) and engine capacities are distinguished. The model is particularly designed for line sources. Therefore, roads are considered as line sources and emissions induced by vehicles are estimated individually for each road segment considering detailed information on traffic flux. Three road segment types can be defined in the road network: urban, rural and motorway. Average speed and vehicles flow per road segment were introduced using TRANUS output results. To characterize fleet composition, statistical data of insurance companies and Portuguese Automotive Commercial Association (ACAP, 2008) were used. The following vehicle categories and their percentage in the fleet were considered for road traffic emission estimation: gasoline passenger cars - GPC (53\%); diesel passenger cars - DPC (23\%); light duty vehicles - LDV (21\%); heavy duty vehicles - HDDV (1\%); diesel urban buses - DUB (1\%); and motorcycles - MPD (1\%). Additionally, these categories were disaggregated by vehicle age, engine capacity, and technology. The same proportional sharing for the vehicle technologies was applied within the road network. Such approach is based on the preliminary study of the monitored data, which presented no relevant oscillations in both spatial and temporal dimensions regarding the fleet composition. The TREM model outputs (pollutant emissions for each road segment) were used in the air quality model.

\subsubsection{Air quality modeling}

The Air Pollution Model (TAPM) is a 3-D Eulerian model which predicts meteorology and air pollution concentrations, based on the fundamental fluid dynamics and scalar transport equations. Technical details of the model equations, parameterisations and numerical methods are described by Hurley et al. (2005). The model integrates two modules: the meteorological and the air pollution component. The first predicts the meteorology parameters that are one of the inputs for the second which predicts the concentration and deposition of the air pollutants.

The air pollution component besides the meteorological outputs considers the air pollutant emissions from several sources, described through the emission files:

- point source emissions ( ${ }^{*}$.pse),

- line source emissions ( ${ }^{*}$.lse), area/volume source emissions ( ${ }^{*}$.ase),

- gridded surface emissions ( ${ }^{*}$.gse), independent of temperature,

- biogenic surface emissions ( ${ }^{*}$.bse), at $\mathrm{T}=30^{\circ} \mathrm{C}$ and $\mathrm{PAR}=1000$ $\mu \mathrm{mol} \mathrm{m} \mathrm{m}^{-2} \mathrm{~s}^{-1}$ for VOC,

- wood heater emissions ( ${ }^{*}$.whe), at $\mathrm{T}=10^{\circ} \mathrm{C}$ for all pollutant species,

- vehicle petrol exhaust emissions ( ${ }^{*}$.vpx), at $\mathrm{T}=25^{\circ} \mathrm{C}$ for $\mathrm{VOC}, \mathrm{NO}_{\mathrm{x}}$ and $\mathrm{CO}$,

- vehicle diesel exhaust emissions ( $\left.{ }^{*} . \mathrm{vdx}\right)$, independent of temperature,

- vehicle LPG exhaust emissions ( ${ }^{*}$.vlx), at $\mathrm{T}=25^{\circ} \mathrm{C}$ for $\mathrm{VOC}, \mathrm{NO}_{\mathrm{x}}$ and $\mathrm{CO}$ and

- vehicle petrol evaporative emissions ( ${ }^{*}$.vpv), at $\mathrm{T}=25^{\circ} \mathrm{C}$ for VOC.

TAPM has some options regarding pollution calculations: it can be without calculations (None), one tracer mode (TR1), two tracer modes (TR1 and TR2), four tracer modes (TR1, TR2, TR3, and TR4), a chemistry mode without sulphur and fine particle chemistry (APM, $\mathrm{NO}_{\mathrm{x}}, \mathrm{NO}_{2}$, and $\mathrm{O}_{3}$ ), a chemistry mode with sulphur and fine particle chemistry (APM, $\mathrm{NO}_{\mathrm{x}}, \mathrm{NO}_{2}, \mathrm{O}_{3}, \mathrm{SO}_{2}$, and $\mathrm{FPM}$ ), or even a dust mode with four particle sizes for $\mathrm{PM}_{2.5}, \mathrm{PM}_{10}, \mathrm{PM}_{20}$ and $\mathrm{PM}_{30}$ (denoted as TR1, TR2, TR3 and TR4 respectively in the model).

The tracer modes do not include chemistry or deposition processes and predicted pollutant concentrations are shown in units of $\mu \mathrm{g} \mathrm{m}^{-3}$. Each tracer can represent either specific groups of sources or emissions for the same pollutant, different pollutants, or a combination of both. In chemistry mode, gas-phase is based on the semiempirical mechanism entitled the Generic Reaction Set (GRS), including also the reactions of $\mathrm{SO}_{2}$ and $\mathrm{PM}$, having 10 reactions for 13 species.

TAPM includes a nested approach for meteorology and air pollution, for computational efficiency, with the pollution grids optionally being able to be configured for a sub region and/or at finer grid spacing than the meteorological grid, which allows a user to zoom-in to an urban region of interest quite rapidly. Meteorological and pollution outputs are in various formats and include vertical and temporal profiles for the several parameters (Hurley et al., 2005).

$\mathrm{CO}$ and $\mathrm{PM}_{10}$ atmospheric concentrations were simulated. The first pollutant was simulated in a tracer mode because it is the only way that TAPM allows the CO simulation, and the second was simulated in a chemistry mode. These pollutants were chosen because both are 
monitored continuously at the AQMS of Aveiro and they are some of the pollutants that are more relevant when dealing with road traffic.

TAPM was applied over the region of Aveiro for the year 2005. The application considered four domains, all with a center over the air quality station of Aveiro (Domain 1: $750 \times 750 \mathrm{~km}^{2}-30 \times 30 \mathrm{~km}^{2}$ resolution; Domain 2: $250 \times 250 \mathrm{~km}^{2}-10 \times 10 \mathrm{~km}^{2}$ resolution; Domain 3: $75 \times 75 \mathrm{~km}^{2}-3 \times 3 \mathrm{~km}^{2}$ resolution; and Domain 4: $25 \times 25 \mathrm{~km}^{2}-$ $1 \times 1 \mathrm{~km}^{2}$ resolution).

The run was performed just using the nested option (one-way). For the air pollution component the emission data was considered only for the innermost domain. Emission data was obtained from the updated Portuguese national inventory, spatially downscaled to the sub-municipality level for pollutant and each activity sector (Monteiro et al., 2007) using the gridded surface emissions ( ${ }^{*}$.gse) type of emissions file. The disaggregation was made until $1 \times 1 \mathrm{~km}^{2}$, needed for the chemistry mode with sulphur and fine particle chemistry and for the tracer mode simulations. Additional emissions input data, concerning traffic emissions over the specific roads of the study area, were included using the line sources emissions (*.lse) type. Traffic emissions were previously estimated by TREM model. Both TRANUS and TREM modeling results corresponded to the previously analyzed morning peak hour. Thus, taking into account the daily traffic behavior (taken from the traffic counts), the total amount was weighted by the specific portion of traffic for each hour. The input background concentrations required by the model were obtained as a result from the analysis of the AQMS monitored values within the study area. Values considered for the chemistry mode and for the tracer mode simulation are presented in Table 2.

The meteorological simulation has been performed for all the mentioned domains. The air pollutant concentration calculation was carried out only for Domain 4, including the AQMS of Aveiro.

\section{Results and discussion}

The sequential modeling process was applied to the case study scenarios. A preliminary comparison study was made to evaluate the TRANUS model applicability to the reference scenario. First, model transportation results were compared with the traffic data measurements to evaluate the reasonability of the model. Then, estimations of fuel consumption, emissions and pollutant concentrations for the baseline scenario were performed. Finally, the alternative future scenarios were tested.

\subsection{Land use and transportation}

This part of the study focuses on TRANUS outcomes, aiming to validate the baseline year (2008) simulation for Aveiro, with the observed traffic flows. Two origin destination matrices, home based work (HBW) and home based services (HBS), were created through the relationships between the defined sectors and a trip generation function. The model assigned $80 \%$ for HBW trips and $20 \%$ for HBS.

Fig. 3 illustrates the plots for observed and modeled traffic volume flows, using both the DE and VR counts. In order to determine whether the model under-estimates or over-estimates the results

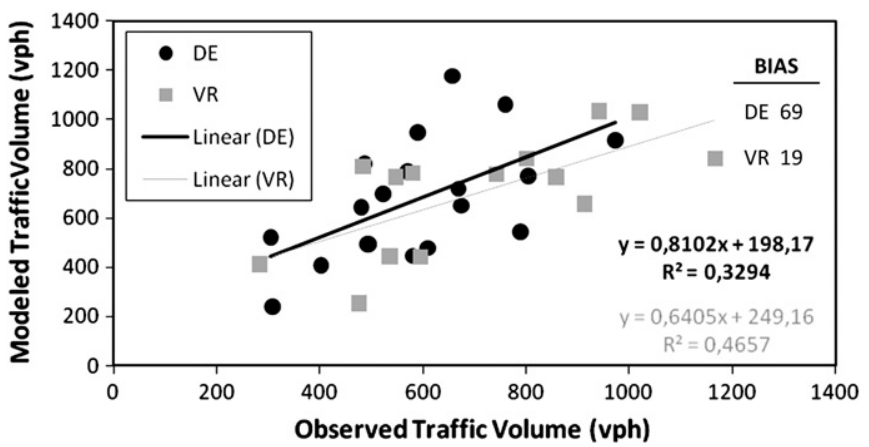

Fig. 3. Observed vs. modeled traffic volume.

observed, BIAS indicator (Eq. (1)) was calculated for both types of monitoring.

BIAS $=\frac{\sum_{i=1}^{N}\left(P_{i}-O_{i}\right)}{N}$

where:

$\mathrm{O}_{i} \quad$ observed values

$P_{i} \quad$ predicted values.

According to BIAS results, it was possible to conclude that the model overestimated the traffic volume flows. Both BIAS and $\mathrm{R}^{2}$ values show better results for VR monitoring, which took place at the entrances of the city.

To evaluate the performance of the TRANUS model for the reference scenario, the statistical analysis recommended by FWWA (1997) was used. The FHWA Model Validation and Reasonableness Checking Manual recommends using Percent Root Mean Square Error (\%RMSE) at the aggregate level, i.e., all $N$ links with counts where the limit value of $30 \%$ is indicated as acceptable to the model validation. The (\%RMSE) is calculated as follows.

$\%$ RMSE $=\frac{\sqrt{\sum_{j}\left(\text { Model }_{j}-\text { Count }_{j}\right)^{2} /(N-1) * 100}}{\left(\sum_{j} \text { Count }_{j} / N\right)}$

The overall \%RMSE calculated was 31.9\% using both the DE and VR traffic counts (sample with a total of 21,121 vehicles). Considering just VR traffic counts, \%RMSE was 25.9\% ( sample with a total of 11,951 vehicles).

To validate the model, FHWA also suggests developing internal cordon lines or boundaries. According to this recommendation, a cordon between A25 and EN109 (see Fig. 2) was designed, to validate the total "inputs and outputs" of the urban core. For the entries in the city center, in the morning peak hour, 6870 vehicles were counted and the TRANUS model assigned 6829. Regarding the outputs, in the same period, a total of 5061 vehicles were monitored and TRANUS model

Table 2

Values considered to the chemistry mode (with sulphur and fine particle chemistry) and the tracer mode.

\begin{tabular}{|c|c|c|c|c|c|c|}
\hline & $\mathrm{PM}_{10}\left(\mathrm{mg} \cdot \mathrm{m}^{-3}\right)$ & $\mathrm{NO}_{\mathrm{x}}(\mathrm{ppb})$ & $\mathrm{SO}_{2}(\mathrm{ppb})$ & $\mathrm{R}_{\mathrm{smog}(\mathrm{ppb})}$ & $\mathrm{O}_{3}\left(\mathrm{mg} \cdot \mathrm{m}^{-3}-\mathrm{ppb}\right)$ & $\mathrm{PM}_{2,5}\left(\mathrm{mg} \cdot \mathrm{m}^{-3}\right)$ \\
\hline \multirow[t]{2}{*}{ Chemistry mode } & 30 & 0.2 & 0.2 & 0.5 & $39.3-20$ & 10 \\
\hline & TR1 $\left(\mathrm{mg} \cdot \mathrm{m}^{-3}\right)$ & TR2 (ppb) & TR3 (ppb) & TR4 (ppb) & $\mathrm{O}_{3}\left(\mathrm{mg} \cdot \mathrm{m}^{-3}-\mathrm{ppb}\right)$ & $\mathrm{PM}_{2,5}\left(\mathrm{mg} \cdot \mathrm{m}^{-3}\right)$ \\
\hline Tracer mode & 100 & 0.2 & 0.2 & 0.5 & $39.3-20$ & 0 \\
\hline
\end{tabular}


output was 5646. The modeled inputs in the urban core are similar to the VR traffic counts. Outputs are overestimated about $12 \%$. Thus, it can be considered that the relationship between the modeled and observed values is acceptable.

\subsection{Fuel consumption and pollutant emissions}

At the morning peak hour, for the simulated road network, emissions of about 12 tons of $\mathrm{CO}_{2}$ were estimated, corresponding to 7.8 tons of fuel consumed. In the same period, for the other pollutants the following emissions were estimated: $99 \mathrm{~kg} \mathrm{~h}^{-1}, 2.7 \mathrm{~kg} \mathrm{~h}^{-1}$, $49.2 \mathrm{~kg} \mathrm{~h}^{-1}$ and $1.51 \mathrm{~kg} \mathrm{~h}^{-1}$, for CO, PM, $\mathrm{NO}_{\mathrm{x}}$ and $\mathrm{VOC}$, respectively. Spatial analysis of fuel consumption showed that the highest levels of fuel consumption occur in the main entrances to the city center, A25 and EN109.

Fig. 4 shows the reference scenario estimated emissions and fuel consumption by vehicle category. Fuel consumption and $\mathrm{CO}_{2}$ emissions are proportional to vehicles distribution by category. Given the operation characteristics of Otto-cycle engine, $\mathrm{CO}$ emitted by gasoline cars represents $77 \%$ of total emissions. For $\mathrm{NO}_{\mathrm{x}}$ and $\mathrm{PM}_{10}$ emissions, diesel vehicles (DPC and LDDV) contribute substantially with $51 \%$ and $77 \%$ of total emissions respectively. Although motorcycles (MPD) represent just $1 \%$ of the vehicles, they are responsible for $32 \%$ of VOC emissions. This can be explained by the VOC emission factor $\left(\mathrm{g} \mathrm{kg}^{-1}\right.$ fuel $)$ (EF) for motorcycles which is much higher $\left(360 \mathrm{~g} \mathrm{~km}^{-1}\right)$ than the factor of gasoline vehicles $\left(8.50 \mathrm{~g} \mathrm{~km}^{-1}\right)$ (EEA, 2005). This could be mainly explained by the considerable employ of two-cycle engines in MPD, which emit more HC than the general four-cycle machines (Vasic and Weilenmann, 2006).

As far as energy use is concerned, at the morning peak hour a total of $3747 \mathrm{~kg}$ of diesel and $4059 \mathrm{~kg}$ of gasoline were consumed, approximately $268 \mathrm{GJ}$ for the entire simulated network.

\subsection{Air quality}

In order to perform a correct validation of the TAPM was important to assess the behavior of each component of the model, comparing the obtained results with the measurements. For that analysis several quality indicators described over the TAPM technical paper (Hurley et al., 2005d) were applied: Bias (Eq. (1)), Index of Agreement, (Eq. (3)), and Measures of Skill (Eq. (4)):

Index of Agreement:

$$
\begin{aligned}
& I O A=1-\frac{\sum_{i=1}^{N}\left(P_{i}-O_{i}\right)^{2}}{\sum_{i=1}^{N}\left(\left|P_{i}-O_{\text {mean }}\right|+\left|O_{i}-O_{\text {mean }}\right|\right)^{2}} \text {, where } \\
& O_{\text {mean }}=\sum_{i=1}^{N} O_{i}
\end{aligned}
$$

Measures of Skill:

$\operatorname{SKILL}_{R}=\frac{R M S E}{O_{\text {std }}}$, where

$$
\begin{aligned}
& O_{\text {std }}=\sqrt{\frac{1}{N-1} \sum_{i=1}^{N}\left(O_{i}-O_{\text {mean }}\right)^{2}} \text { and } \\
& \text { RMSE }=\sqrt{\frac{1}{N} \sum_{i=1}^{N}\left(P_{i}-O_{i}\right)^{2}}
\end{aligned}
$$

$\mathrm{O}_{i} \quad$ observed values

$P_{i} \quad$ predicted values

RMSE Root Mean Square Error

The Index of Agreement (IOA) supplies the difference between the predicted values and the observed values. If this value is higher than 0.5 it is considered that the model has a good performance. In order to consider that the model has a good performance, it is important that the RMSE be lower than the Standard Deviation of the observed values $\left(O_{s t d}\right)$.

The BIAS indicates the tendency of the model to follow the variations of the observed values; if it is positive, the model overestimates the results and otherwise it underestimates the results.

Meteorological module was validated by comparing the estimated model data with the measurements of the meteorological station located at the University of Aveiro. For temperature, wind direction and wind speed the correlation is higher than 0.5 , revealing that the model has a good performance on the simulation of the meteorological parameters (Table 3 ).

Air pollution module validation was performed by a comparison between the measured data in the air quality station of Aveiro and the model results, considering the pollutants CO and PM (Figs. 5 and 6 respectively). The air quality station of Aveiro is a traffic-related station, and the only one of this type in D4 that fulfils the purposes of the work. Furthermore, this assumption follows the work of Borrego et al. (2010), in which the model TAPM has already been applied for different types of air quality stations presenting a good performance. Both components were validated just for the winter period (November and December) like the traffic monitoring.

Regarding a qualitative analysis of CO (Fig. 5), TAPM always provides lower concentrations than those measured, demonstrating that the model underestimates the concentrations. However, considering PM, the two curves present a similar behavior, indicating a higher correlation between the modeling results and the measurements. Table 3 presents the quality indicators for both pollutants. The

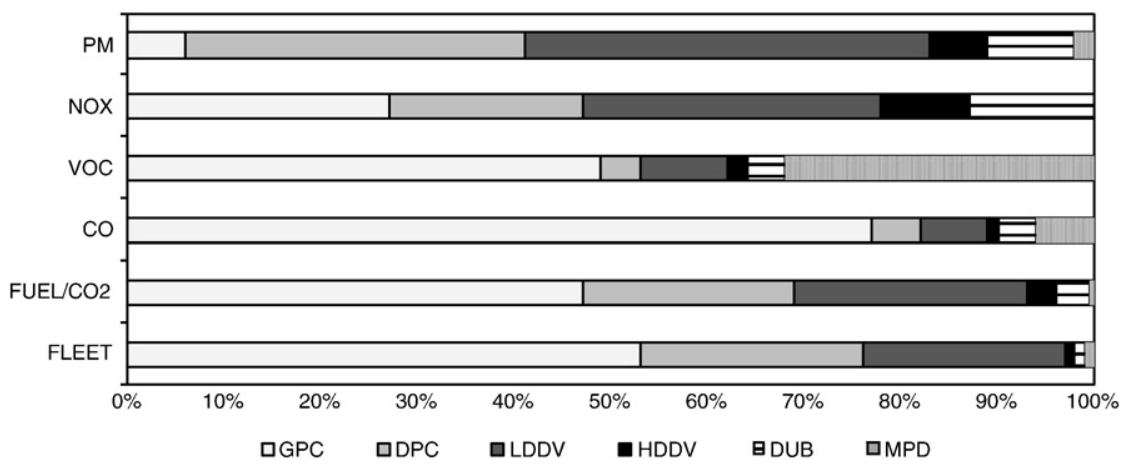

Fig. 4. Pollutant emissions and fuel consumption relative percentage by vehicle category. 
Table 3

Indicators of quality for weather and air pollution.

\begin{tabular}{|c|c|c|c|c|c|c|}
\hline \multirow[t]{2}{*}{ Parameter } & \multirow[t]{2}{*}{ Reference } & \multicolumn{3}{|c|}{ Weather } & \multicolumn{2}{|c|}{ Air pollution } \\
\hline & & $\begin{array}{l}\text { Wind } \\
\text { speed }\end{array}$ & Temperature & $\begin{array}{l}\text { Wind } \\
\text { direction }\end{array}$ & $\mathrm{CO}$ & PM \\
\hline r & 1 & 0.53 & 0.92 & 0.81 & 0.41 & 0.52 \\
\hline IOA & $>0.5$ & 0.69 & 0.95 & 0.87 & 0.47 & 0.66 \\
\hline SkillR & $<1$ & 0.75 & 0.11 & 0.01 & 1.48 & 1.08 \\
\hline Bias & 0 & - & - & - & 284.41 & 0.97 \\
\hline
\end{tabular}

model does not show high quality indicators for all the parameters related to $\mathrm{CO}$ concentrations. Also noteworthy is the lower value (0.41) for the correlation. A preliminary justification to some of the observed deviations is related to the model characteristics. Although the maximum resolution of the model $\left(1 \mathrm{~km}^{2}\right)$ could be considered reasonable, this tool lacks the ability to simulate small-scale variations in traffic patterns, and does not allow simulating the local conditions of the air quality station accurately enough. In addition, it is known that the speed variations, namely accelerations, influence CO emissions (Coelho et al., 2005). The air quality station is located near a traffic light intersection, typically a stop-and-go "hotspot", which increases CO emissions (Coelho et al., 2005, 2009b). Another possible explanation for these deviations is the lack of a strong based knowledge on the source of exceptional emissions and the background pollutant concentrations, particularly concerning CO. Comparative analysis between the model results and the measured PM concentrations shows a good performance of the model (IOA discrepancy index $>0.5$ ). The capacity index (SkillR) is slightly higher than the recommended value (1). Bias is 0.95 , showing that the model somewhat underestimates the values. It is reasonable to assume that the model is coherent with the monitoring, concerning the PM concentration. The results also suggest that TAPM has better performance when the chemistry mode is used instead of the tracer mode.

Concerning $\mathrm{CO}$ the maximum concentration is predicted for the city center, where traffic density is higher. For the city center, the average annual $\mathrm{CO}$ concentration is $235 \mu \mathrm{g} \mathrm{m}^{-3}$. Regarding $\mathrm{PM}_{10}$ concentration, the maximum annual average value is $44 \mu \mathrm{g} \mathrm{m}^{-3}$ (limit legal value of $40 \mu \mathrm{g} \mathrm{m}^{-3}$ ) southeast from the city center.

\subsection{Alternative scenarios}

The analysis of the alternative scenarios (scenario 1 and scenario 2) for the Domain 4 was performed considering the year of 2005. Scenario 1 was simulated by imposing a mean occupancy rate of 3

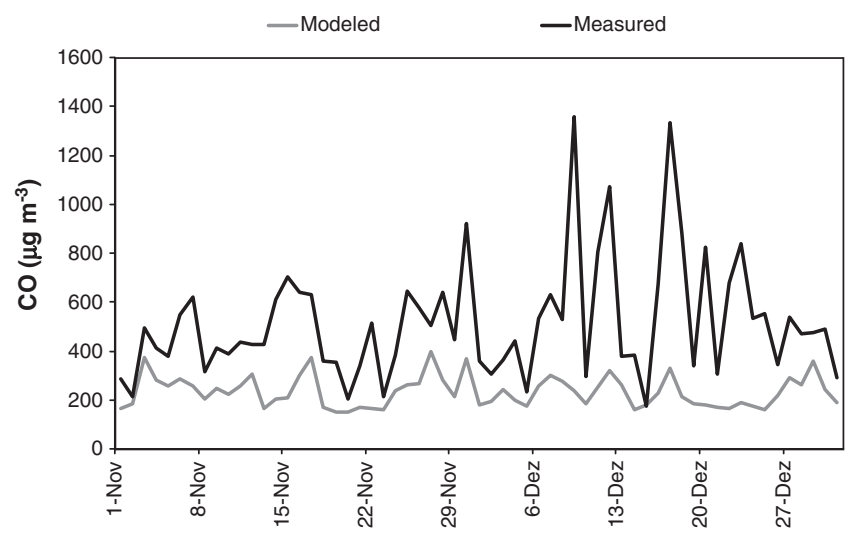

Fig. 5. Modeled and measured CO concentrations.

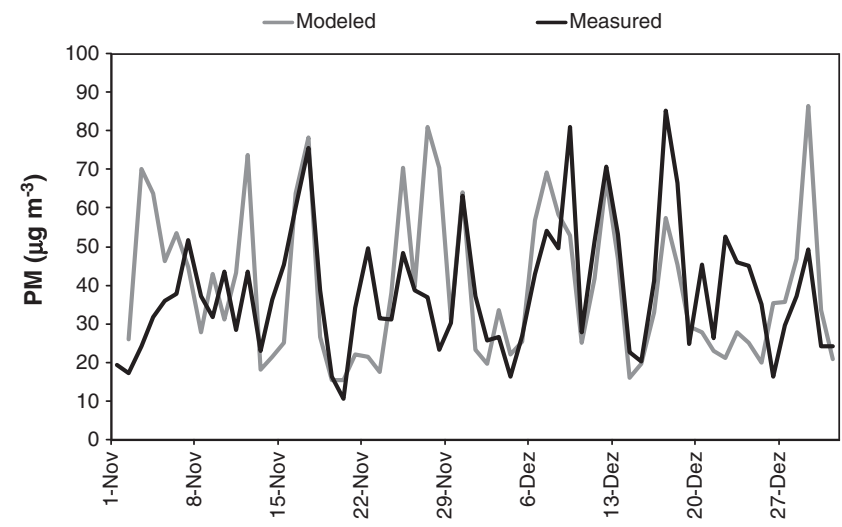

Fig. 6. Modeled and measured PM concentrations.

passengers by vehicle (instead of the observed average 1.5 in the reference scenario). As a result, and adding a simulated decrease in the average trip price, the number of displacement would increase (more passengers, lower trip price) but the number of vehicles would drop. There would be an averaged decrease of $45 \%$ of the vehicles circulating in the analyzed road network during the morning peak hour. Fig. 7 illustrates the new traffic distribution with this scenario, in comparison with the baseline scenario, with the traffic flow assignment to each link at the morning peak hour.

The analysis of scenario 2 takes only into account the results of the emissions model and the air quality model, since the traffic characteristics remained constant.

For scenario 1 there is an overall decrease of all pollutants by $44 \%$ except for CO which showed a higher reduction (54\%) due to the decrease in the use of gasoline passenger cars. For scenario 2, all pollutants express a very significant reduction, always higher than the reduction obtained for scenario 1 , even with more vehicles circulating. $\mathrm{CO}, \mathrm{NO}_{\mathrm{x}}, \mathrm{VOC}$ and $\mathrm{PM}_{10}$ emissions are reduced in about $83 \%, 79 \%$ and $87 \%$ and $95 \%$ respectively. Actually, the Euro 6 standards, for $\mathrm{PM}_{10}$ pollutant, are particularly challenging, since reductions up to $97 \%$ for standard Euro 1 are imposed. Concerning fuel consumption and $\mathrm{CO}_{2}$ emissions, whereas scenario 1 allows a reduction of $44 \%$, the reduction for scenario 2 is negligible (around 1\% decrease).

Fig. 8a shows $\mathrm{CO}$ and $\mathrm{PM}_{10}$ concentrations for the baseline scenario and the differentials of the annual average concentration fields of $\mathrm{CO}$ and $\mathrm{PM}_{10}$ for both the simulated scenarios. (Fig. 8b and c). For the reference scenario, $\mathrm{CO}$ annual average concentration calculated by the model is approximately $235 \mu \mathrm{g} \mathrm{m}^{-3}$. In the city center there is a potential reduction of about $100 \mu \mathrm{g} \mathrm{m}^{-3}$ for both considered situations. For $\mathrm{PM}_{10}$ concentrations, the changes are not significant. In scenario 1 for the city center, the maximum reduction would be from $1.35 \mu \mathrm{g} \mathrm{m}{ }^{-3}$ while the annual average concentration estimated for the baseline scenario was of $36 \mu \mathrm{g} \mathrm{m}^{-3}$. For scenario 2 the reduction reaches $2.7 \mu \mathrm{g} \mathrm{m}^{-3}$. The background concentrations in the examined area and the concentrations found in the border regions may explain the small changes observed.

\section{Conclusions}

This paper has presented the application of an integrated modeling platform in a Portuguese medium-sized city. The mobility patterns of Aveiro have been evaluated, and the urban road-traffic related fuel consumption and atmospheric pollutant emissions have been estimated.

Regarding transportation model, both the overall comparison of simulated and monitored traffic (which showed an RMSE\% of 31\%) and the accounting of total traffic volume entering and leaving the urban core ( $1 \%$ and $12 \%$ of deviations for inputs and outputs, respectively) 
a)

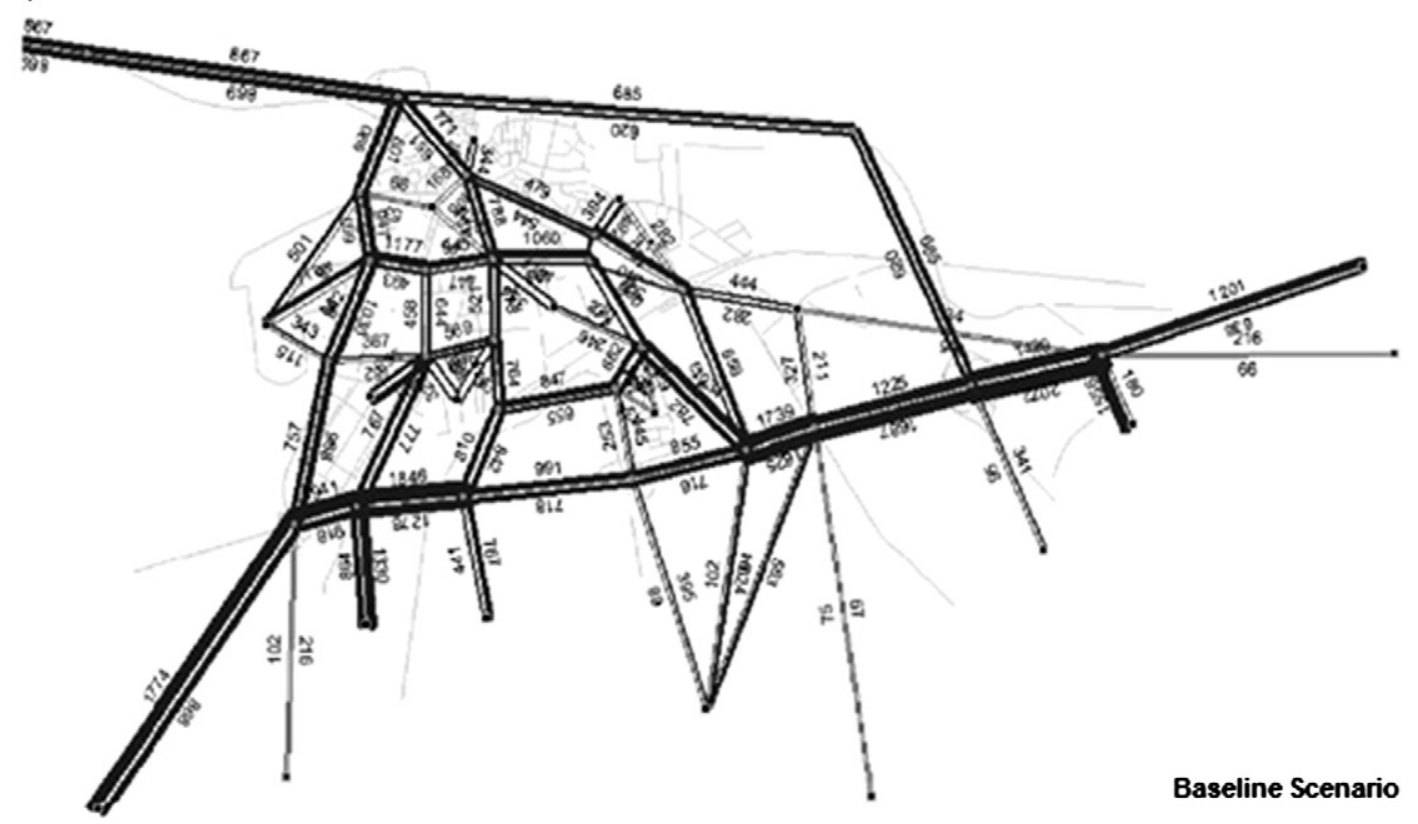

b)

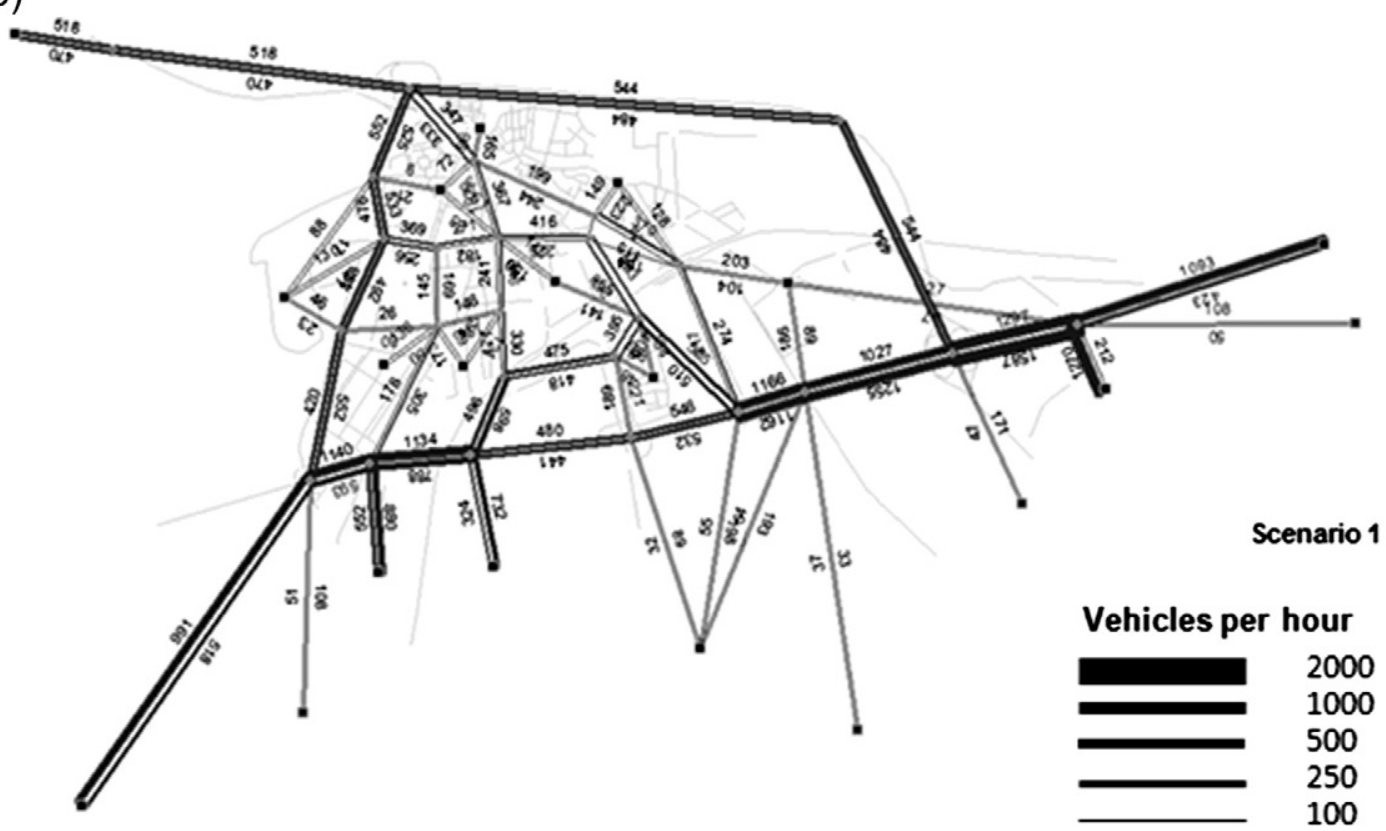

Fig. 7. Assigned traffic in the morning peak hour for: a) baseline scenario and b) car-pooling scenario.

showed consistent results. Given the city dimensions and its administrative structure, the data collection for urban neighborhood was particularly difficult. At this scale it was proved that it is possible to build a model that reasonably reflects the baseline scenario, based on empirical factors and with a light structure. Nevertheless, in future work more independent data would be needed to verify the model predictions, and to minimize transfer errors that occur when a model or parameters developed for one context or region are applied in a different one.

Emissions and fuel consumption were estimated for the main urban network at the morning peak hour. However, further micro simulation of individual urban actors behavior would be useful for evaluating the magnitudes of errors in prediction that may result for macro-simulation models.
Regarding air quality, the simulation of $\mathrm{CO}$ concentrations showed poor quality indices, partly justified by the unawareness of the parameters needed for the run of the tracer mode, such as the pollutant decay rate. However, the modeled $\mathrm{PM}_{10}$ concentration demonstrated high consistence with the reality. The results also indicate a better performance when using the chemistry mode as a replacement for the tracer mode.

Scenario 1 shows that it is possible to reduce $\mathrm{CO}$ in $54 \%$ and $\mathrm{NO}_{\mathrm{x}}$, $\mathrm{PM}_{10}$, VOC and $\mathrm{CO}_{2}$ emissions in $44 \%$, if the occupancy rate of the vehicles is doubled. Scenario 2 reveals that there were reductions exceeding $80 \%$ for $\mathrm{CO}, \mathrm{NO}_{\mathrm{x}}$, $\mathrm{VOC}$ and $\mathrm{PM}_{10}$ emissions due to increased efficiency in controlling vehicle emissions.

In both scenarios, the annual average concentration of $\mathrm{PM}_{10}$ remains high indicating that probably the implementation of other 
a)
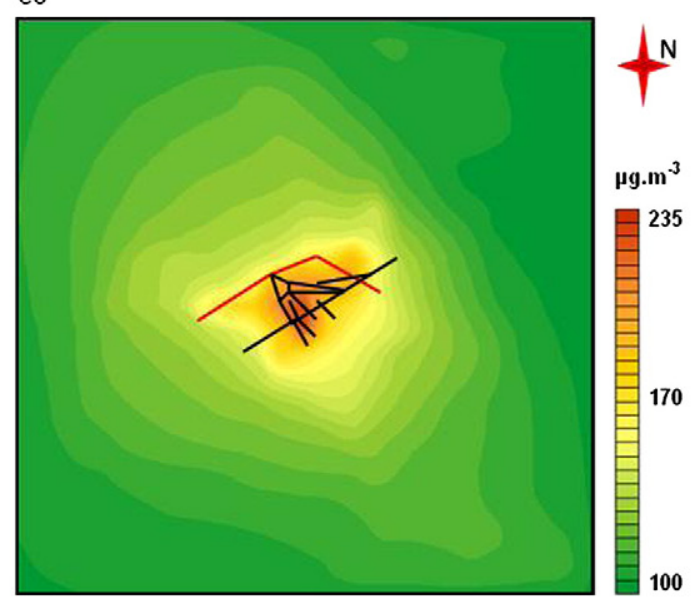

b)
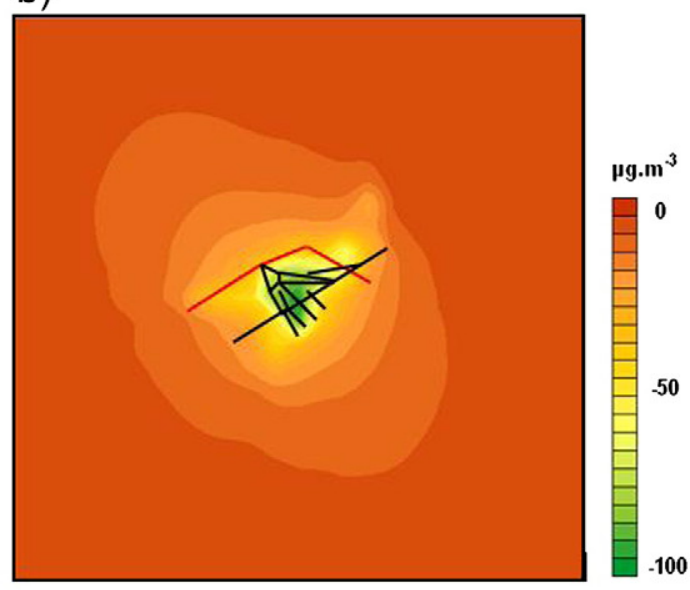

c)

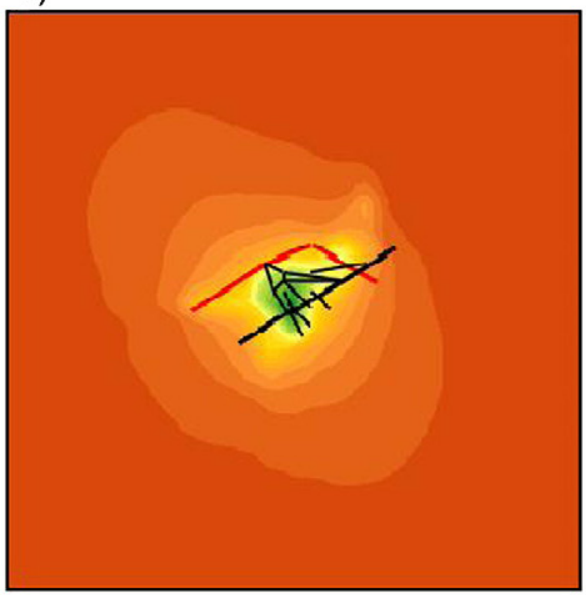

100

\section{PM10}

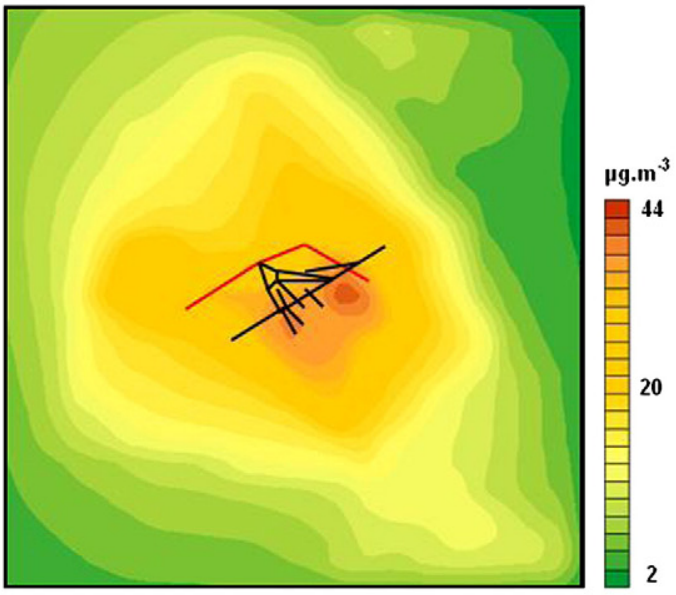

2
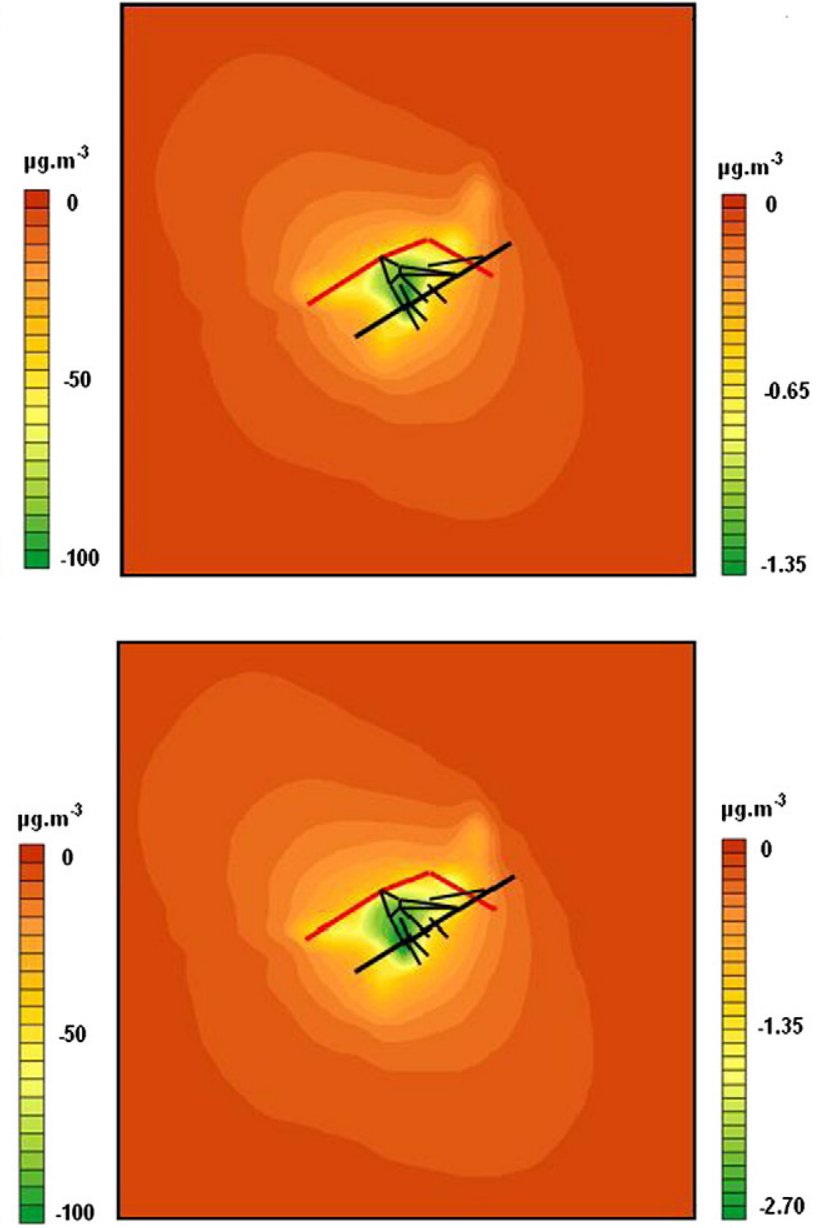

Fig. 8. $\mathrm{CO}$ and $\mathrm{PM}_{10}$ concentrations for: a) baseline scenario. Reduction of annual average concentrations with alternative scenarios: b) scenario 1 and c) scenario 2 .

measures outside the scope of transportation will be essential for the reduction of $\mathrm{PM}_{10}$ concentration.

This work intended not only to analyze how land use influence the current mobility patterns but also to assess what would be the effect of mobility policy changes in the existing circumstance of land occupation. Having a model of land use and transportation calibrated to the current situation could be a starting point to further modeling, being the land use pattern itself the main variable. The reasonable results achieved in transportation model and air quality model, namely PM concentrations encourage the application of the methodology used in other medium sized urban areas.

\section{Acknowledgments}

The authors would like to acknowledge the financial support of the Portuguese Ministry of Science, Technology and Higher Education, through the Foundation for Science and Technology (FCT), for the PhD grants of J.F. Bandeira (SFR/BD/66104/2009), M.E. Sá (PTDC/AMB/ 
69599/2006), and R. Tavares (SFRH/BD/22741/2005) and the PostDoctoral grant of M.C. Coelho (SFRH/BPD/21317/2005). The authors would also like to acknowledge the Luso-American Foundation (Project 91-03/2010, within the Program FLAD/NSF - "PortugalUSA: Networks and Partnerships for Research"). The authors also acknowledge to the Aveiro Municipality, for the traffic volumes data, and to Prof. Asad Khattak, Prof. Nagui Rouphail and Dr. Brian Morton (respectively from Old Dominion University, Institute for Transportation Research and Education of North Carolina State University and University of North Carolina at Chapel Hill), for the information and feedback on TRANUS.

\section{References}

ACAP: Portuguese Association of Car Manufacturers [Internet]. Statistics on fuel economy [cited 2008 Nov 20]. Available from: http://www.acap.pt.

Borrego C, Tchepel O, Costa A, Amorim J, Miranda A. Emission and dispersion modeling of Lisbon air quality at local scale. Atmos Environ 2003;37:5197-205.

Borrego C, Martins H, Tchepel O, Salmim L, Monteiro A, Miranda A. How urban structure can affect city sustainability from an air quality perspective. J Environ Model Softw 2006;21:461-7.

Borrego C, Sá E, Carvalho A, Sousa J, Miranda A. Plans and programmes to improve air quality over Portugal: a numerical modelling approach. Proceedings of the 13th International Conference on Harmonisation within Atmospheric Dispersion Modelling for Regulatory Purposes, 1-4 June, Paris, France; 2010.

Civerolo K, Hogrefe C, Lynn B, Rosenthale J, Ku J-Y, Solecki W, et al. Estimating the effects of increased urbanization on surface meteorology and ozone concentrations in the New York City metropolitan region. Atmos Environ 2007;41:1803-18.

Coelho M, Farias T, Rouphail N. Impact of speed control traffic signals on pollutant emissions. Transp Res D 2005;4:323-40.

Coelho M, Frey H, Rouphail N, Zhai H, Pelkmans L. Assessing methods for comparing emissions from gasoline and diesel light-duty vehicles based on microscale measurements. Transp Res D: Transport Environ 2009a;14(2):91-9.

Coelho M, Farias T, Rouphail N. TEDS (Traffic \& Emission Decision Support) - a numerical tool for estimating emissions and traffic performance on urban corridors. Int J Sustainable Transp 2009b;3(4):246-62.

de la Barra T, Brown F, Rickaby P, Turner J, Steadman P. Integrated Land Use and Transport Model for the Energy and Environmental Evaluation of Urban Policies: the City of Swindon [Internet]. Modelistica, Open University, Manchester University, Swindon County Council; 1998 [cited 2008 Oct 09]. Available from: http://www.modelistica.com/swindoneng.htm.

De Ridder K, Lefebre F, Adriaensen S, Arnold U, Beckroege W, Bronner C, et al. Simulating the impact of urban sprawl on air quality and population exposure in the Ger Ruhr area. Part I: reproducing the base state. Atmos Environ 2008a;42(30): 7059-69.

De Ridder K, Lefebre F, Adriaensen S, Arnold U, Beckroege W, Bronner C, et al. Simulating the impact of urban sprawl on air quality and population exposure in the German Ruhr area. Part II: development and evaluation of an urban growth scenario. Atmos Environ 2008b;42(30):7070-7.
DieselNet. On-line information service on clean diesel engines and diesel emissions [Internet]. Emission Standards [cited $2010 \mathrm{Fev}$ 8] Available from:http://www. dieselnet.com/standards/eu/ld.php.

EC - Commission for the European Communities. Green Paper - towards a new culture for urban mobility [Internet]; 2007. Brussels [cited $2008 \mathrm{Sep} 22$ ]. Available from: http://www.ec.europa.eu/transport/clean/green_paper_urban_transport/.

EEA. EMEP/Corinair - European Environmental Agency emission inventory guidebook [Internet]; 2005 [cited 2009 Mar 06]. Available from:http://www.eea.europa.eu/ publications/EMEPCORINAIR.

EEA. Towards a resource-efficient transport system. TERM 2009: indicators tracking transport and environment in the European Union; 2010 [internet] [cited 2010 Aug 06]. Available from:http://www.eea.europa.eu/publications/towards-a-resourceefficient-transport-system.

FWWA. Barton-Aschman Associates, Inc. and Cambridge Systematics, Inc. Travel Model Improvement Program Model Validation and Reasonableness Checking Manual [Internet]. Federal Highway Administration; 1997 [cited 2008 Oct 28]. Available from:http://www.tmip.fhwa.dot.gov/node/124.

Hurley P, Physick W, Luhar K. TAPM: a practical approach to prognostic meteorological and air pollution modelling. Environ Modell Softw 2005;20:737-52.

INE: Portugal Statistics [Internet]. Censos 2001 [cited 2010 Mar 5] Available form:http: //www.ine.pt/xportal/xmain?xpgid=ine_main\&xpid=INE.

Johnston A, de la Barra T. Comprehensive regional modeling for long-range planning: linking integrated urban models and geographic information systems. Transp Res A 2000;34(2):125-36.

Kousoulidou M, Ntziachristos L, Mellios G, Samaras Z. Road-transport emission projections to 2020 in European urban environments. Atmospheric Environment 2008;42:7465-75.

Lam T, Niemeier D. An exploratory study of the impact of common land-use policies on air quality. Transp Res D 2005;10(55):365-83.

Marquez L, Smith N. A framework for linking urban form and air quality. Environ Model Softw 1999;14(6):541-8.

Marshall J, McKoneb T, Deakind E, Nazaroff W. Inhalation of motor vehicle emissions: effects of urban population and land area. Atmos Environ 2005;39:283-95.

Modelistica. TRANUS: integrated land use and transport model - general description [Internet] Caracas; 2007 [cited 2008 Oct 09]. Available from:http://www. modelistica.com/tranus english.htm.

Monteiro A, Miranda A, Borrego C, Vautard R, Ferreira J, Perez A. Long-term assessment of particulate matter using CHIMERE model. Atmos Environ 2007;41:7726-38.

Morton B, Rodriguez D, Song Y, Cho E. Using TRANUS to construct a land usetransportation-emissions model of Charlotte, North Carolina. Proceedings of the transportation land use, planning, and air quality conference 2007, Orlando, FL; 2007.

PLUME. Project planning and urban mobility in Europe - synthesis report, land use planning measuresEVK4-CT-2002-20011; 2003. [cited 2009 Dec 14]. Available from:http://www.cabri-volga.org/DOC/EG4/PLUME.pdf.

Pooley C, Turnbull J. Coping with congestion: responses to urban traffic problems in British cities c. 1920-1960. J Hist Geogr 2005;31(1):78-93.

Reid E, Bartholomew K, Winkelman S, Walters J, and Chen D Growing. The evidence on urban development and climate change. Washington, DC 2008. Urban Land Institute, Smart Growth America, Center for Clean Air Policy and National Center for Smart Growth Education and Research 2008.

Vasic A, Weilenmann M. Comparison of real-world emissions from two-wheelers and passenger cars. Environ Sci Technol 2006;40(1):149-54.

Williams K, Burton E, Jenks M. Achieving sustainable urban form. London: E \& FN Spon; 2000. 